\author{
Halina Karaś \\ Uniwersytet Warszawski \\ Instytut Języka Polskiego \\ ORCID: 0000-0003-4383-9626; e-mail: h.a.karas@uw.edu.pl
}

\title{
Jeszcze o potrzebie dokumentowania leksyki gwarowej (na przykładzie wybranych wyrazów południowomałopolskich z okolic Biecza)
}

\begin{abstract}
Abstrakt: Celem artykułu jest zwrócenie uwagi na potrzebę dokumentowania leksyki gwarowej. Mimo iż polska dialektologia może poszczycić się wieloma opracowaniami, to jednak ciągle przekonujemy się podczas badań terenowych, że dokumentacja słownictwa gwarowego jest niepełna. W artykule na przykładzie wybranych wyrazów południowomałopolskich odnotowanych we wsiach Bugaj i Sitnica pokazuję, jak wiele jeszcze dialektyzmów jest nieudokumentowanych, nieodnotowanych w istniejących źródłach, albo też jak ich poświadczenia są niepełne, zwłaszcza w zakresie różnych ich znaczeń.
\end{abstract}

Słowa kluczowe: leksykografia gwarowa, leksyka gwarowa, dokumentacja, gwary małopolskie.

\begin{abstract}
Even need for documenting dialectal lexics (on the example of selected words from South Malopolska around Biecz). The aim of the article is to draw attention to the need of documenting the dialect lexicon. While Polish dialectology can boast of many publications, field studies continue to confirm that the documentation of dialect vocabulary is incomplete. In this article I have selected a few words from Southern Poland recorded in the villages of Bugaj and Sitnica to show how many dialect variants remain undocumented, not noted in the existing sources, or how their credentials are incomplete, especially in terms of their different meanings.
\end{abstract}

Keywords: dialectal lexicography, dialectal lexis, documentation, dialects of Małopolska (Lesser Poland).

Dokumentowanie słownictwa gwarowego nie jest rzeczą łatwą. Mimo dużej liczby słowników gwarowych oraz monografii, w których uwzględniano również leksykę, czy wyborów tekstów gwarowych i szeroko nieraz zakrojonych studiów, nierzadko stykamy się z sytuacją, że jeszcze obecnie w badaniach terenowych odnotowujemy słownictwo nieznane czy w niepoświadczonych do tej pory znaczeniach lub postaci formalnej.

Choć już pod koniec XX wieku Jan Mazur $(1990,114)$ pisał o nasyceniu materiałowym badań dialektologicznych, to wciąż, po prawie trzydziestu latach, które minęły od tej wypowiedzi, w zakresie leksyki brakuje ukończonego słownika ogólnogwarowego (nie uwzględniając oczywiście dzieła Jana Karłowicza), a licznie ostatnio opracowywane słowniki regionalne i lokalne (profesjonalne i amatorskie) dostarczają nowych danych leksykalnych.

Szczególnie wyraziście uświadomiłam sobie potrzebę gromadzenia gwarowej leksyki, jej dokumentowania w ostatnim czasie, gdy zaczęłam pracować nad słownikiem 
mojej Mamy, Barbary Karaś. Jest Ona rodowitą bugajanką, mieszkanką niewielkiej wsi Bugaj położonej na Pogórzu w okolicach Biecza i Gorlic, a więc w zachodniej części południowo-wschodniej Małopolski. Dialektologicznie to część zachodnia Pogórza Wschodniego (według Stanisława Urbańczyka).

Badania nad słownictwem okolic Biecza i Gorlic były już prowadzone, ale w żadnym $\mathrm{z}$ istniejących słowniczków nie uwzględniono gwary mojej wsi rodzinnej. $\mathrm{Z}$ tego regionu - części Pogórza wschodniego - pochodzą trzy słowniczki, w tym dwa amatorskie, opracowane przez autochtonów, miłośników gwary. Pierwszy to Słownik gwary Pogórzan (z okolic Gorlic) opublikowany w 2011 roku przez Aleksandra Wietrzyka, który gromadzeniu słownictwa Pogórzan poświęcił wiele lat życia. Nie ma jednak przykładów użyć wyrazów gwarowych i dokładnej lokalizacji poza wskazaniem ogólnie na okolice Gorlic, a zatem nie może służyć jako pewna podstawa badań porównawczych, choć oczywiście może ułatwić orientację w zasięgu wyrazów gwarowych. Drugi to Słownik wyrazów i zwrotów językowych $w$ Bobowej $i$ w najbliższych jej okolicach częściej lub rzadziej używanych Ryszarda Kobaki, drugie wydanie tej pracy poprawione i poszerzone ukazało się w 2009 roku, wciąż jednak znacznie uboższe niż słownik Wietrzyka. Bobowa to miejscowość położona ok. $26 \mathrm{~km}$ na zachód od Gorlic. Trzeci słowniczek związany z terenem tej części Pogórza Wschodniego został opracowany przez językoznawcę i zawarty w pracy dialektologicznej - monografii gwary Rzepiennika Strzyżewskiego, wsi gminnej położonej obecnie w powiecie tarnowskim, ale stosunkowo blisko Bugaja - ok. 14 km na północny zachód od mojej rodzinnej wsi (Kucharzyk 2003). Tylko ten słownik zawiera to, co istotne dla dialektologa, a mianowicie obszerne konteksty użycia - wraz ze wskazaniem na informatorów, a więc z dokładną lokalizacją (wieś, informator). Pozostałe dwa słowniczki amatorskie niewątpliwie są cenne, ale nie mają waloru naukowego $\mathrm{z}$ uwagi na brak kontekstów i w pierwszym z nich - brak dokładnej lokalizacji.

Pracę nad słownikiem, nad zbieraniem materiału językowego do niego, rozpoczęłam przy okazji przygotowywania witryny internetowej Gwary polskie. Przewodnik multimedialny (Karaś 2008). Na jej potrzeby opracowałam informacje dotyczące dawnej ziemi bieckiej, opisałam jej gwarę, kulturę, dzieje i współczesność. Rozszerzona wersja tego studium została następnie umieszczona na nowej stronie internetowej portalu o bardziej naukowym charakterze - Dialekty $i$ gwary polskie. Kompendium internetowe (Karaś 2010). W tym miejscu został też zamieszczony Słowniczek wyrazów gwarowych typowych dla Bugaja i okolic mojego autorstwa, liczący wówczas nieco ponad 1000 wyrazów, opracowany w najprostszy sposób: wyraz gwarowy i jego znaczenie. W kolejnych latach przy okazji odwiedzin mojej rodziny zbierałam do niego materiały. Szczególnie zależało mi na znalezieniu odpowiednich kontekstów, które pokazywałyby słowo w użyciu, w otoczeniu innych słów. To zawsze jest najcenniejsze, jak mogłam się przekonać, badając polskie słowniki gwarowe (Karaś 2011), w tym również popularnonaukowe, nierzadko amatorskie, powstałe $\mathrm{z}$ potrzeby serca, $\mathrm{z}$ chęci ocalenia słownictwa gwarowego, języka stron rodzinnych.

Zgromadzony materiał leksykalny okazał się interesujący. W trakcie jego zbierania uważałam, że raczej nie pozyskam nic unikatowego, gdyż gwara mojej rodzinnej wsi i okolic szybko zanika. Wraz z przemianami cywilizacyjno-kulturowymi i językowymi w całej Polsce i tu ginie wraz z realiami, których dotyczy, typowe słownictwo gwaro- 
we. Odchodzi pokolenie najstarsze użytkowników gwary, a wraz z nimi wiedza o niej i o dawnych zwyczajach językowych, kulturowych, o życiu na wsi w przeszłości. Wydawało mi się, że większość słownictwa w naszej gwarze to wyrazy znane w Małopolsce południowej, a więc właściwe gwarom prawie całego Pogórza i pasa górskiego, czy też jeszcze szerzej znane w większości gwar małopolskich lub poza nią. Niektóre wyrazy mają przecież charakter ogólnogwarowy czy prawie taki, występując w gwarach na wielu obszarach.

Zebrana leksyka została sprawdzona w polskich słownikach gwarowych:

1) ogólnogwarowych - w Slowniku gwar polskich Jana Karłowicza, w Stowniku gwar polskich PAN, w Matym stowniku gwar polskich, w Kartotece Stownika gwar polskich PAN,

2) dialektalnym - dotyczącym Małopolski, tj. w Stowniku gwar matopolskich pod red. J. Wronicz,

3) regionalnych - obejmujących różne regiony gwarowe Małopolski, zwłaszcza Małopolski południowej, a więc w słownikach gwar Pogórzan okolic Gorlic (Wietrzyk 2011), Lachów Sądeckich (Szewczyk 2014), gwary gorczańskiej (Kobylińska 2001), gwary górali żywieckich (Nowak 2012), gwary podhalańskiej (LGiKP), orawskiej (SGO), w tym również nieco bardziej odległych obszarów, np. gwary opoczyńskiej (Cygan 2018), Lubelszczyzny (Pelcowa 2012-2017),

4) lokalnych - jednej lub kilku/kilkunastu wsi, zwłaszcza z południowej Małopolski, np. gwary Rzepiennika Strzyżewskiego na Pogórzu (Kucharzyk 2003), gwary lasowiackiej Kamienia i okolicy na Rzeszowszczyźnie (Kutyła 2016), gwary wsi Wola Radziszowska koło Krakowa (Jurczyk 2009), gwary gminy Wiśniowa w powiecie myślenickim (2018).

Porównałam też zgromadzony materiał leksykalny ze słownikami regionalizmów, zwłaszcza krakowskich, często mających szeroki, blisko ogólnomałopolski charakter (Ochmann, Przybylska 2017) i krośnieńskich (Bielak, Sikora 2005). W miarę potrzeb zostały wykorzystane w celach porównawczych także słowniki ogólne języka polskiego - historyczne i współczesne, słowniki etymologiczne itp.

Porównanie ze słownikami gwarowymi i słownikami regionalizmów pozwoliło na zorientowanie się w stopniu udokumentowania leksykograficznego badanych wyrazów. Dzięki temu można było wyróżnić grupę dialektyzmów niepoświadczonych (czy słabo poświadczonych) w słownikach lub odnotowanych w innych znaczeniach czy nieco innej postaci formalnej (słowotwórczej i fonetycznej z zachowaniem niesystemowych, często zleksykalizowanych cech fonetycznych). Jest to dowód, jak wiele jeszcze pozostało do zbadania w zakresie leksyki gwarowej, jak ważne jest dokumentowanie obecnie funkcjonującego słownictwa gwarowego czynnego i biernego, niekiedy już zapomnianego. Warto przytoczyć tu przykłady niektórych dialektyzmów zebranych w mojej wsi rodzinnej, by teza o „braku nasycenia materiałowego” w polskiej leksykografii gwarowej została odpowiednio uargumentowana.

Przykładowo - w moim materiale znalazły się nieznane słownikom rzeczowniki: cholas, duźda, oraz czasowniki: cieryntać - ocieryntać, skrukwieć, które przedstawiam wraz ze znaczeniami i kontekstami:

CHOLAS 'urwis, chuligan': Cholas to taki chtopok niedobry, to jest cholas. Taki z niego cholas niedobry. Jakiesi cholasy tak zdespetowali, ze teroz nic ni można zrobić. Bug.BK; 
DUŹDA 'gołąbka zielona': Bytem w lejsie, nazbierołem dużo duźdów, cosik z tego trza zrobić. Bug.SK; Taki głód byt, to poleciałam do lasca, najadłam sie krówek, surowe duźdy, a duźdy to trza piyc. Bug.BK;

CIERYNTAĆ - OCIERYNTAĆ 'poruszać, wprawiać w ruch, kołysać - poruszyć, wprawić w ruch, ukołysać': Maryna nie widziała, to miała śnurek przywiónzany do kojski i caty cos cieryntała tom kojskom, nawet jak dziecko spało. Bug.TM;

SKRUKWIEĆ 'skruszeć': Moze niepotrzebnie dzisiok jesce wjechot, ziymia mokro, błoto, lepi było płocekać, zeby skrukwiało. Chłojco tak skrukwieje fajnie, z jedzynia, a i drzewo moze skrukwieć, 'ono sie rozłazi. Bug.BK.

Wymienione wyrazy nie zostały poświadczone ani w słownikach ogólnogwarowych (Jana Karłowicza i opracowywanym przez PAN), ani w Słowniku gwar małopolskich, ani w słownikach poświęconym poszczególnym gwarom Małopolski południowej (podhalańskiej i orawskiej Józefa Kąsia [LGiKP; SGO], gorczańskiej Józefy Kobylińskiej [2001], Lachów Sądeckich Zenona Szewczyka [2014], lasowiackiej Jana Kutyły [2016]), w szczególności gwarom powiatu gorlickiego Aleksandra Wietrzyka (2011), ani w monografii Rzepiennika Strzyżewskiego Renaty Kucharzyk (2006). Nie ma również tego rzeczownika w Kartotece SGP PAN w materiałach zdygitalizowanych i zamieszczonych w Internecie.

Pierwszy z tych wyrazów może się ewentualnie wiązać z rzeczownikiem żeńskim cholastra 'kobieta lubiąca dużo mówić, zuchwale odpowiadać, zwłaszcza skłonna do hałaśliwych kłótni' i czasownikiem cholastrować 'dużo mówić, zuchwale i głośno, kłócić się’ (por. SGPPAN IV, 11) przytoczonymi w Słowniku gwar polskich z Kaszub (Puck wej), słabo zresztą udokumentowanymi (pojedyncze poświadczenia). Drugi duźda ma - co prawda - formalne nawiązania w czasowniku duźdać 1) 'gnieść, miażdżyć' (koniń); 2) 'miąć, miętosić' (łęcz); 3) 'bóść' (płoc); 4) 'robić coś niestarannie, partaczyć' (Maz pn); i w rzeczowniku duźdaj ekspres 'o człowieku niezdarnym, niezgrabnym' (mrąg - SGOWM II, 134). Niełatwo jednak zrekonstruować proces ewolucji znaczenia, tym bardziej, że notacje wskazują na zupełnie inne obszary gwarowe (centralna i północna Polska). Na bardziej odpowiedni trop poszukiwań naprowadza Barbara Bartnicka, która w monografii Polskie ludowe nazwy grzybów poświadczyła z okolic Limanowej, a więc również z Pogórza, ale z jego zachodniej części, nazwę grzyba duzia - łac. Russula virescens (Bartnicka-Dąbkowska 1964, 87). Z kolei przywołane czasowniki gwarowe bez dokumentacji cieryntać - ocieryntać trudno powiązać z innymi dialektyzmami, być może nastąpiła w nich jakaś znaczna zmiana formalna, fonetyczna, która utrudnia ich identyfikację. Podobnie rzecz wygląda $\mathrm{z}$ czasownikiem skrukwieć, którego odpowiednikiem niedokonanym byłaby zapewne forma krukwieć, także niepoświadczona leksykograficznie. Można je wiązać z rdzeniem kruch- (a -chprzechodzi w - $k$ - w gwarach południowomałopolskich, zwłaszcza w grupie spółgłoskowej, tu $c h w>k w$ ). Wskazuje na to odnotowana w Stowniku gwar polskich Jana Karłowicza w artykule hasłowym kruchy (SGPKJ, II, 486) forma adiektywna krukwy, np. mięso krukwe, poświadczona z rękopiśmiennego Stowniczka gwary od Ropczyc Seweryna Udzieli (1857-1937), etnografa i współpracownika Jana Karłowicza. Jego słowniczek dziś znany tylko z haseł w słowniku Karłowicza nigdy nie został opublikowany (por. Karaś 2010). Warto podkreślić, że okolice Ropczyc w zasadzie należą do tego samego regionu Pogórza Wschodniego, co Bugaj i okolice, choć znajdują się już na 
północnowschodnim krańcu tego obszaru (ok. 60 km od Bugaja), blisko granicy rozdzielającej Małopolskę późniejszą od pierwotnej, ale jeszcze w części mazurzącej.

Nie posiada dokumentacji w leksykografii gwarowej także cała rodzina wyrazowa: herzt, (robić/pracować) na herzcie, herztowo, herztowy, herztować. Określa ona pracę na przedzie i osoby ją wykonujące, a więc nadawanie tempa pracy przez osoby wynajmowane w tym celu, por. hasła w opracowanym przeze mnie słowniku gwary Bugaja:

HERZT 1) rzecz. mos. 'dawniej: mężczyzna pracujący na przedzie i nadający tempo pracy': Ludzie narzykali na tyk herztów, bo straśnie szybko robili i nie mogli nadónzyć. Bug.BK; 2) w wyrażeniu: NA HERZCIE; NA HERZT 'dawniej o pracy: pracować na przedzie i nadawać tempo pracy': Na herzcie jak sie downi kopało, to na herzcie sie dawało takiego chłopa abo kobiete, co pryndko robit cy robiła. Wiyncy zawsze płacili tymu, co byt na herzcie, to piyrsy sed. Downi to zamowiali ludzie na herzt. Downi to na herzcie wybiyrali takie kobiyty, co umiały dobrze kopać. I na tym herzcie tak dowodzity, ze ni mogli ludzie zdónzyć. Bug.BK.

HERZTOWO rzecz. $\dot{z}$. 'dawniej: kobieta pracująca na przedzie i nadająca tempo pracy’: Kobiyta na herzcie to herztowo, to chodzito o to, zeby pryndzy robić. Bug.BK.

HERZTOWAĆ czas. ndk. 'dawniej o pracy: pracować na przedzie i nadawać tempo pracy’: Kto na przód sed, to hesztowot. Ludzie narzykali na tyk hesztów, bo straśnie pryndko robili $i$ nie mogli nadónzyć. Bug.BK.

HERZTOWY przym. 'dotyczący osoby, która pracowała NA HERZCIE, czyli na przedzie': Wiyncy widziałam herztowe kobiyty. Bug.BK.

Wymienione wyrazy w słownikach gwarowych nie są w ogóle udokumentowane, jedynie Słownik gwar polskich Jana Karłowicza z początku XX wieku notuje w podobnej postaci i znaczeniu wyraz hersznik 'zeniec, który przy robocie był pierwszy' za pracą Seweryna Udzieli, Lud polski w pow. ropczyckim (SGPJ II, 181). W słownikach historycznych i w słowniku etymologicznym Franciszka Sławskiego natomiast te słowa mają ciekawe poświadczenia. Niewątpliwie nawiązują do wyrazów dawnych, a ich znaczenia można uznać za archaiczne i jednocześnie innowacyjne. W polszczyźnie XVI wieku wyraz herst \| herszt miał i konotacje pozytywne, i negatywne. Stownik polszczyzny XVI wieku poświadcza jego stosowanie w znaczeniu neutralnym 'wódz, przywódca', podobnie czasownik herstować \| hersztować oznaczał ogólnie 'przewodzić', zwrot herst wodzić to 'rządzić, prym, rej wodzić', wyskoczyć na herst 'stanąć na czele wojska' (SPXVI VIII, 334), a więc oba zwroty określały wysunięcie kogoś na czoło, przewodzenie. Już jednak w XVI wieku znaczenie wyrazu herszt zaczęło się zmieniać, nabierać negatywnych skojarzeń i oznaczać 'przywódcę złych ludzi lub złej sprawy', a więc nastąpiła degradacja znaczenia. Z pochodzenia wyraz herszt to germanizm, czyli zapożyczenie z niemieckiego, prawdopodobnie z śrgniem. hērst, hērist 'pierwszy, głowa, naczelnik' (SEJPSław I, 417). W gwarze Bugaja herst (sz w herszt ulega mazurzeniu, czyli jest wymawiane jako $s$ ) wymawia się jako xešt ze względu na mocną tendencję do uproszczeń i upodobnień. Grupę $r s$ artykułuje się - podobnie jak W wielu gwarach południowomałopolskich - w sposób uproszczony jako r $\breve{\mathrm{r}}$ ( $)$, por. inne wyrazy z wymienioną grupą: gorztka, worztwa = garstka, warstwa (AGP I, m. 34 $r s>\check{r})$.

Wyrazy herzt, na herzcie, herztowo, herztować poświadczają zatem dawne archaiczne znaczenie 'przywódca', 'na przedzie', 'przewodzić' (bez negatywnego nacechowania), 
ale też jednocześnie innowacyjne, gdyż chodzi o przewodzenie w pracy, a więc odnoszą się one do tych osób, które przewodzą $\mathrm{W}$ pracy, nadają tempo pracy. W ten oto sposób dawne wyrazy i dawne ich znaczenia pozostały w gwarze, choć w nieco zmodyfikowanej zarówno postaci (formie), jak i w znaczeniach. Jednocześnie te wyrazy pokazują, jak gwara odzwierciedla obraz świata jej użytkowników, wyznawane przez nich wartości, zwyczaje (jak choćby te związane z wynajmowaniem ludzi umiejących szybko i dobrze pracować na herzt) itp.

W zgromadzonym materiale jest również grupa wyrazów poświadczających inną postać formalną, np. fonetyczną. Jako przykład można przytoczyć czasownik rozgraczyć się 'rozkraczyć się', który w tej postaci nie został odnotowany w żadnym z uwzględnionych słowników gwarowych. Niekiedy wyraz ma poświadczenia, ale bardzo rzadkie, czasem znaczenie różni się w mniejszym lub większym stopniu, np. przymiotnik spacny i przysłówek spacnie, por.

SPACNIE przyst. 'dziwacznie, odwrotnie, niejasno': Tata to chłoćkiedy tak spacnie godo, jak Bernad, nie wiadómo, kiedy prawde godo. Bug.BK.

SPACNY przym. 'dziwaczny, dziwny, taki, który robi odwrotnie': Julka to tako spacno, stale cosik przeinacy. Bug.TM.

Przysłówek spacznie $=$ na wspak poświadczył Jan Karłowicz (SGPKJ, V, 192) za słowniczkiem Oskara Kolberga z Krakowskiego bez kontekstu. Przymiotnik spaczny znajduje się też w materiałach Kartoteki Słownika gwar polskich PAN (przysłówka brak) - ryb 'o wietrze: przeciwny' (Kaszuby); 'taki, któremu włosy sterczą nad czołem ku górze’ (Jodłowa jas.), spaczny - spacna mowa (Pisarzowa lim), i to znaczenie i użycie jest najbliższe odnotowanemu przeze mnie. W pozostałych słownikach, w tym w słowniku Pogórzan okolic Gorlic obu wyrazów nie zarejestrowano. Przytoczone przeze mnie przykłady są zatem cenne, zarówno z uwagi na znaczenie, jak i geografię tych wyrazów.

Nierzadkie są też przykłady wyrazów różniących się nieznacznie pod względem formalnym i znaczeniowym, sporadycznie poświadczonych, bez kontekstów, z innych pobliskich regionów. Odnotowanie ich w mojej gwarze z obszernymi przykładami użycia poszerza wiedzę o ich geografii, ewolucji znaczenia i formy. Dobrze ilustruje to rzeczownik tyrtuła:

TYRTUŁA rzecz. $\dot{z}$. 'kobieta gadatliwa, dużo i głośno mówiąca': A to z Kondy była tyrtuła, jak przysła, to ino godała, to sie natyrcała, to godali, to taka tyrtuła z ni. Tyrtuła to tako, co duzo i głośno godo. Bug.BK.

Wyraz ten został poświadczony tylko na Orawie w SGO J. Kąsia bez cytatów $\mathrm{w}$ podobnej postaci i w podobnym znaczeniu: tyrtula 'kobieta mówiąca wiele, ale naprawdę niezdecydowana ani we własnych opiniach, sądach, ani w postępowaniu’. Brak poświadczeń tego rzeczownika w uwzględnionych słownikach: ogólnogwarowych, dialektalnym, regionalnych i lokalnych (por. ich wykaz). Jedynie w słowniku Jana Karłowicza (SGPKJ, V, 399) zarejestrowany został czasownik tyrtolić (hasło tertolić) w kilku znaczeniach, z których jedno niewątpliwie wiąże się z omawianym rzeczownikiem: tyrtolić = partolić, źle coś robić, gadać itp.: szewc stertolił mi buty. 'Natertolił' = nawygadywał (z Kolberga, Krakowskie); tyrtolić = niezgrabnie prać (S. Udziela, Słowniczek gwary od Ropczyc - rękopiśmienny); tyrtolić = gadać od rzeczy (Dembowski, Słownik gwary podhalskiej). 
Materiał leksykalny z gwary Bugaja zawiera też ciekawe formacje słowotwórcze, np. czasowniki prefiksalne, do tej pory nieudokumentowane, por. wyzdziwiać się pochodny od zdziwiać:

WYZDZIWIAĆ SIE czas. $d k$. 'nadokazywać, nagrymasić się, nawydziwiać; nacudować': Godali, ze jak sie dziecko wyzdziwio, to późni jest spokojne. Bug.BK. Por. ZDZIWIAĆ.

Czasownik niedokonany zdziwiać ma zasięg ograniczony do Małopolski południowej (por. SGM, II, 165; MSGP, 351; SGPKJ, VI, 363; Kutyła 2016, 327; Szewczyk 2014, 786; brak w pozostałych uwzględnionych słownikach. Formacja prefiksalna nie została natomiast leksykograficznie udokumentowana.

Dane gwarowe mogą także służyć do badań etymologii wyrazów ogólnopolskich, np. odnotowane w gwarze Bugaja wyrazy kurdawy i kurdoc mogą przyczynić się do właściwej etymologizacji wyrazu kurdupel w polszczyźnie, w słownikach uznawanego za niejasny pod względem pochodzenia. Rzeczownik kurdoc oznacza 'lichy, słaby, drobny ziemniak' i nie ma żadnych poświadczeń leksykograficznych, tj. nie został odnotowany w żadnym słowniku gwarowym z terenu Małopolski ani w ogólnogwarowych (Stownik gwar polskich Jana Karłowicza i nowy Słownik gwar polskich opracowywany przez Polską Akademię Nauk). Pokrewny przymiotnik kurdawy 'lichy, słaby, drobny, niedorosły do naturalnej wielkości' (moja Mama stwierdziła, że ch ${ }^{\dagger}$ ojco może być kurdawe, drzewo, roślina, zimnioki) ma tylko jedno poświadczenie w Kartotece SGP PAN 'niedorosły do naturalnej wielkości (człowiek, zwierzę, roślina)' ze Słownika okolicy Czchowa Władysława Kosińskiego, opracowanego w latach 80. XIX wieku, wydanego drukiem po śmierci autora w 1915 roku (Karaś 2011, 108). Przymiotnik o tej samej podstawie słowotwórczej, ale utworzony innym przyrostkiem -owaty, a więc kurdowaty odnotował Jan Karłowicz bez podania znaczenia, ze znakiem zapytania, przywołując cytat z pism Wincentego Pola, w którym wystąpiło wyrażenie drzewa kurdowate (SGPKJ II, 530). W świetle zebranych materiałów można stwierdzić, że chodzi o liche, niskie, słabo rosnące drzewa. Kolejny wyraz pokrewny - czasownik kurdawieć 'karłowacieć, słabo rosnąć, usychać' poświadczył Jan Kutyła (2016, 122) w swoim amatorskim Stowniku gwary lasowiackiej Kamienia i okolicy na Rzeszowszczyźnie, podobnie z Przewrotnego (Rzeszowskie) odnotowano kurdewieć w tym samym znaczeniu w Kartotece SGPPAN. Z oddalonego od Bugaja o ok. $14 \mathrm{~km}$ na zachód Rzepiennika Strzyżewskiego poświadczyła skurdawieć 'o roślinach: zmarnieć, zniszczeć w początkowej fazie rozwoju’ Renata Kucharzyk (2003, 91). Widać zatem, że w części gwar południowomałopolskich w użyciu znajdowała się cała rodzina wyrazowa kurdawy || kurdowaty, kurdawieć - skurdawieć, kurdoc, których znaczenia dotyczyły niedorośnięcia do naturalnej wielkości - człowieka, zwierzęcia, rośliny. W ich świetle motywuje się ogólnopolski wyraz kurdupel 'człowiek niskiego wzrostu, który nie dorósł do naturalnej wielkości’, a więc omówione wyrazy gwarowe (KURDAWY, KURDOC) mogą posłużyć do etymologizacji wyrazu ogólnopolskiego.

Kolejny ciekawy przykład, który dostarcza interesujących danych do badań nad leksyką gwarową, to czasownik hankorzyć się 'kłócić się ostro, gwałtownie': Tak sie straśnie kłóci z drugim, tak sie hankorzy. Tak sie hankorzyła, ze nie było pojyncia i o co ji chłodziło do dziźnia nie wiym. Bug.BK. W tej postaci formalnej i znaczeniu wyraz nie został odnotowany, gdyż w SGP PAN czasownik hankorzyć się został 
odesłany do rankorzyć się (hasło jeszcze nieopracowane). W Kartotece SGP PAN (materiały zdygitalizowane) jedyne poświadczenie czasownika hankorzyć się z nagłosowym $h$ - pochodzi z Mszany Górnej w okolicach Limanowej, ale w znaczeniu nieco innym 'zezłościć się, rozgniewać się'. Poza tym poświadczona jest forma jankorzyć się 'smucić się’ z Żywiecczyzny (Koszarawa, Korbielów). Obie postaci zostały powiązane $\mathrm{z}$ rankor i znajdują się $\mathrm{w}$ materiałach na literę $\mathrm{R}$ (z odesłaniem do rankorzyć się, mimo iż poświadczono jedynie formy $z$ nagłosowym $h-i j$-, a więc ze spółgłoskami protetycznymi. W żadnym słowniku gwarowym - ogólnogwarowym Jana Karłowicza (SGPKJ), Słowniku gwar małopolskich pod red. J. Wronicz (SGM), w słownikach autorskich Józefa Kąsia (LGiKP, SGO), Słowniku Lachów Sąeckich Zenona Szewczyka (2014), Słowniku gwary Pogórzan (z okolic Gorlic) Aleksandra Wietrzyka (2011) nie odnotowano tego czasownika. Nie został też poświadczony w monografii Renaty Kucharzyk (2003) poświęconej gwarze Rzepiennika Strzyżewskiego, ani w artykule Moniki Bielak i Kazimierza Sikory (2005) o regionalizmach krośnieńskich. Poświadczenie zatem tego tak rzadkiego czasownika hankorzyć w gwarze mojej rodzinnej wsi na Pogórzu daje ważną wskazówkę co do jego geografii i rozwoju jego znaczeń.

Można przytoczyć jeszcze szereg interesujących wyrazów z gwary Bugaja, których poświadczenia mogą się okazać cenne dla pracy leksykografów gwarowych, przede wszystkim dla powstania słownika ogólnogwarowego. Już nawet jednak omówione tu przykłady pokazują, że istnieje jeszcze potrzeba dokumentacji leksyki gwarowej, tym pilniejsza, iż odchodzi najstarsze pokolenie, które nawet jeśli czynnie nie włada gwarą, to przechowuje ją w zasobie biernym, zwłaszcza słownictwo. Okazuje się, że nieraz są to prawdziwe ,perły”.

\section{Bibliografia:}

AGP I, Dejna K. (1998), Atlas gwar polskich, t.1: Małopolska, Warszawa.

AJPP, Małecki M., Nitsch K. (1934), Atlas językowy polskiego Podkarpacia, cz. 1-2, Kraków (cz. 1, 500 map; cz. 2, Wstęp, objaśnienia, wykazy wyrazów).

APID, Dejna K. (1981), Atlas polskich innowacji dialektalnych, Warszawa.

Bartnicka-Dąbkowska B. (1964), Polskie ludowe nazwy grzybów, Wrocław-Warszawa-Kraków.

Bielak M., Sikora K. (2005), O regionalizmach leksykalnych $w$ języku Krosna i okolic, [w:] Literatura - Język-Region, red. K. Sikora i J. Kułakowska-Lis, Prace Naukowo-dydaktyczne PWSZ w Krośnie, z. 17, Krosno, s. 7-28.

Cygan S. (2018), Stownik gwary opoczyńskiej, Opoczno.

ESJPSław, Sławski F. (1952-1956), Etymologiczny słownik języka polskiego, t. 1 (A-H), Kraków. Jurczyk I. (2009), Stownik gwary wsi Wola Radziszowska, Wola Radziszowska.

Karaś H. (red.), (2008), Gwary polskie. Przewodnik multimedialny, www.gwarypolskie.uw.edu.pl.

Karaś H. (red.) (2010), Dialekty i gwary polskie. Kompendium internetowe, www.dialektologia. uw.edu.pl.

Karaś H. (2011), Polska leksykografia gwarowa, Warszawa.

Kobaka R. (2009), Słownik wyrazów i zwrotów językowych w Bobowej używanych, wyd. II popr. i poszerz., Warszawa. 
Kobylińska J. (2001), Stownik gwary gorczańskiej (zagórzańskiej), Kraków.

Kucała M. (1957), Porównawczy słownik trzech wsi matopolskich, Wrocław.

Kucharzyk R. (2003), System fonetyczny i leksykalny wsi Rzepiennik Strzyżewski w ujęciu socjolingwistycznym, Kraków 2003.

Kucharzyk R. (2006), O podziałach dialektu małopolskiego, [w:] Studia dialektologiczne III, red. J. Okoniowa, Kraków, s. 33-46.

Kurek H. (2003), Przemiany leksyki gwarowej na Podkarpaciu, Kraków.

Kutyła J. (2016), Stownik gwary lasowiackiej Kamienia i okolicy na Rzeszowszczyźnie, Rzeszów.

LGiKP, Kąś J. (2014-2019), Ilustrowany leksykon gwary i kultury podhalańskiej, t. I-III, Bukowina Tatrzańska, t. IV-XII, Kraków-Nowy Sącz.

Mazur J. (1990), Dialektometria a nowe koncepcje i metody kartograficznego przedstawiania zjawisk gwarowych, „Rozprawy Komiscji Językowej Łódzkiego Towarzystwa Naukowego”, t. XXXV.

MSGP, Mały stownik gwar polskich, red. J. Wronicz, Kraków 2009.

Nowak J.K. (2012), Słownik gwary górali żywieckich, Żywiec-Grojec-Warszawa.

Ochmann D., Przybylska R. (red.) (2017), Powiedziane po krakowsku. Słownik regionalizmów krakowskich, Kraków.

Pelcowa H. (2012-2017), Stownik gwar Lubelszczyzny, t. I-V, Lublin.

Pych E. (2016), Leksyka gwary wsi Jamnica, Kamionka Mała oraz Popowice koło Nowego Sacza, praca magisterska napisana na Wydziale Polonistyki Uniwersytetu Warszawskiego pod kierunkiem H. Karaś, Warszawa.

SGM, Stownik gwar małopolskich, red. J. Wronicz, t. 1-2, Kraków 2016-2017.

SGO, Kąś J. (2011), Stownik gwary orawskiej, t. I-II, wyd. II popr. i poszerz., Kraków.

SGOWM, Stownik gwar Ostródzkiego, Warmii i Mazur, t. I: A-Ć, red. Z. Stamirowska, Wrocław-Warszawa-Kraków-Gdańsk-Łódź 1987, t. II: D-G, red. Z. Stamirowska, WrocławWarszawa-Kraków 1991, t. III: H-K, red. Z. Stamirowska i H. Perzowa, Warszawa-Kraków 1993, t. IV: L-N, t. V: O-Ó, red. H. Perzowa i D. Kołodziejczykowa, Warszawa-Kraków 2002, 2006.

SGPKJ, Karłowicz J. (1900-1911), Stownik gwar polskich, t. I-VI, Kraków 1900-1911.

Sikora K. (2017), Zagadnienie trwałości gwarowego stownictwa w języku młodych mieszkańców wsi (na przyktadzie kilku gwar poludniowej Małopolski), [w:] Dynamika rozwoju gwar stowiańskich w XXI wieku, red. D.K. Rembiszewska, Warszawa, s. 157-167.

Stownictwo i kultura ludowa gminy Wiśniowa, red. zbior., Wiśniowa 2018.

SPXVI, Stownik polszczyzny XVI wieku, red. M. Mayenowa i in., t. VIII, Wrocław 1974.

Szewczyk Z.P. (2014), Stownik gwary Lachów Sądeckich (Podegrodzkich), Podegrodzie.

Wietrzyk A. (2011), Słownik gwary Pogórzan (z okolicy Gorlic), pod red. nauk. B. Grabki i R. Kucharzyk, Gorlice. 